\title{
Niam Txiv Txoj Kev Txawj Ntse: A Psychosociocultural Understanding of Hmong Parents' Support of their Hmong American Undergraduates
}

\author{
Pa Her \\ Alberta M. Gloria \\ Shee Yee Chang \\ Pahoua Thao \\ Douachong Lee \\ Maimoua Xiong \\ University of Wisconsin-Madison \\ USA
}

\begin{abstract}
This qualitative study examines the narratives of support that 8 sets and 2 singlemother Hmong parents (10 mothers and 8 fathers) provided their children pursuing higher education. Ten 90-minute semi-structured interviews were conducted in Hmong parents' homes. Using a psychosociocultural approach, narratives were analyzed using a multi-step process, yielding three emergent themes for both Hmong parents and two specific to mothers and fathers, respectively. Findings clearly reveal the importance of Hmong parent home practices and processes to support their child in higher education. Implications for university personnel working to establish educational partnerships with Hmong parents and communities to support Hmong student persistence are addressed.
\end{abstract}

Keywords: Hmong parents, educational encouragement, Hmong undergraduates 
Despite the fact that many Hmong parents lack a formal education from their homeland in Laos or Thailand, they highly value the importance of obtaining a higher education degree (Faderman \& Xiong, 1998; Her \& Gloria, 2016). Many Hmong parents believe education is the route out of poverty and therefore strongly encourage their children to pursue a degree beyond high school as a means of familial advancement (DePuow, 2003). Yet there exists a lack of research examining parents' educational knowledge, support, and values with their son(s) or daughter(s) in higher education. To gain an understanding of Hmong parents' role in higher education, we took a qualitative approach structured within a psychosociocultural framework (Gloria \& Rodriguez, 2000) to examine parents' educational experiences and support of their child (son and daughter) who was attending a four-year public university. To frame the basis of the study's question a brief overview of Hmong history, family, and education is presented.

\section{History of Hmong}

Hmong, an ethnic minority group with a complex political history, resided in China as early as the eighteenth century (Yang, 2003). Due to political, religious, and social reasons, the Chinese government persecuted the Hmong, resulting in their resettlement in southern China and Southeast Asian countries (e.g., Laos, Thailand, Vietnam) (Vang \& Flores, 1999). The Hmong resettled in the mountainous areas of these countries and were primarily slash-and-burn farmers with limited access to education (Paik, Rahman, Kula, Saito, \& Witenstein, 2016; Vang \& Flores, 1999), given the need to farm for survival purposes (Lee, 2005). The Hmong in the United States are primarily those who resettled in Laos and were recruited by the US Central Intelligence Agency (CIA) during the 1960s to gather intelligence about North Vietnamese movements in Laos (Hamilton-Merritt, 1992; Lee et al., 2017) during the Vietnam War. Due to their participation in the War, the Hmong were granted refugee status and allowed resettlement to western countries such as France, Australia, Canada, and the United States (Yang, 2003). As there is a high heterogeneity of Asian ethnicities in the US who often do not share similar immigration or educational experiences (Paik et al., 2016), it is important to understand specific differences, in particular for more recent immigrant groups such as the Hmong, who primarily reside in the states of California, Minnesota, and Wisconsin living among their clan (Karon, Long, \& Veroff, 2003; Lee, Xiong, Pheng, \& Vang, 2017). 


\section{Hmong Family and Education}

Many Hmong place high priority on family, clan system, and sense of community. The Hmong clan system plays a vital role in family life when making important decisions, such as supporting marriages, resolving family problems, and creating interventions (Tatman, 2004). With the highest value, the eldest man in the family frequently has the power to make final decisions (Trimm, 1994). As a patrilineal group, Hmong gender roles are distinct (Moua, 2003), with traditional Hmong women providing for their children and taking care of the home (Lamborn \& Moua, 2008), while the men provide for their family as the breadwinner (Vang \& Flores, 1999). In their homeland of Laos and Thailand, Hmong abided by traditional gender roles dictated by farming responsibilities, which made obtaining formal education difficult.

Educational opportunities were often scare as most villages did not have schools until after the mid-1960s (Inui, 2015). As a result, few families were able to afford schooling for their children beyond an elementary education and when they were able to do so, it was most often the Hmong male children who were privileged to attend school (Inui, 2015).

\section{Hmong in US Higher Education}

Since immigrating to the United States, many Hmong parents believe that obtaining an education paves the way out of poverty (Chung \& Bemak, 2006). As such, Hmong parents hold clear expectations and provide encouragement for their children to earn an education as a means to support and advance their family (DePuow, 2003; Gloria et al., 2017; Her \& Gloria, 2016). With the Hmong population among the youngest in the United States, with $50 \%$ under the age of 24 (US Census Bureau, 2016), focusing on the factors that contribute to their educational success is needed. The educational attainment of Hmong individuals 25 years or older are: a quarter have a high school or equivalent degree, $30.1 \%$ have received an associate degree or attended some college, $13.9 \%$ received a bachelor's degree, and $4.1 \%$ have obtained graduate degrees (US Census Bureau, 2016). Although the attainment levels are not comparable to other racial and ethnic groups, Hmong families generally hold high expectations for their sons and daughters to earn postsecondary degrees (Gloria et al., 2017; Juang \& Meschke, 2017; Lor, 2003). As a young population (US Census Bureau, 2016), Hmong are increasingly represented in school environments and thus having an accurate understanding of those factors that facilitate wellbeing and ultimate graduation is warranted. 
The extant research on Hmong undergraduates' educational experiences contain equivocal findings. Some research suggests that Hmong American students are underachieving in the educational system (Fuertes, Sedlacek, \& Liu, 1994; Lee, 2001), whereas other studies indicate that their academic performance is equivalent to or better than the general undergraduate population (Swartz, Lee, \& Mortimer, 2003). Additionally, Hmong students were found to have higher levels of educational attainment (e.g., bachelor's degree) than their non-Hmong counterparts (Swartz et al., 2003). Although quantitative research on Hmong American undergraduates did not yield the expected familial roles in persistence decisions (Sengkhammee et al., 2017), a qualitative study found that Hmong parents played a significant role and had substantive influence on the students' drive, motivation, and persistence to gain an education (Gloria et al., 2017). These Hmong students also shared that their parents provided tangible support such as money and food and expected them to rau siab or study hard in school (Gloria et al., 2017).

\section{Psychosociocultural Model of Academic Persistence}

For this study we used the psychosociocultural (PSC; see Figure 1) framework (Gloria \& Rodriguez, 2000) as it integrates and contextualizes interrelated dimensions (i.e., psychological, social, and cultural) in understanding undergraduates' educational experiences that form the daily processes of staying in school (i.e., academic persistence). More specifically, the processes of self-beliefs and perceptions (psychological), connections and relationships (social), and cultural approaches and worldviews (cultural) serve to inform students' processes of persistence (Gloria \& Rodriguez, 2000). Emphasizing the non-cognitive dimensions of students' educational persistence experiences, the approach has been empirically validated with different racial and ethnic undergraduates (e.g., Gloria, Castellanos, Lopez, \& Rosales, 2005; Thompson, JohnsonJennings, \& Nitzarim, 2013), including Asian Americans (Gloria \& Ho, 2003) and Hmong Americans (Lin, Her, \& Gloria, 2015; Sengkhammee et al, 2017). The whole-student approach posits that the dimensions individually and collectively inform students' experiences within a learning context (Gloria \& Rodriguez, 2000). 


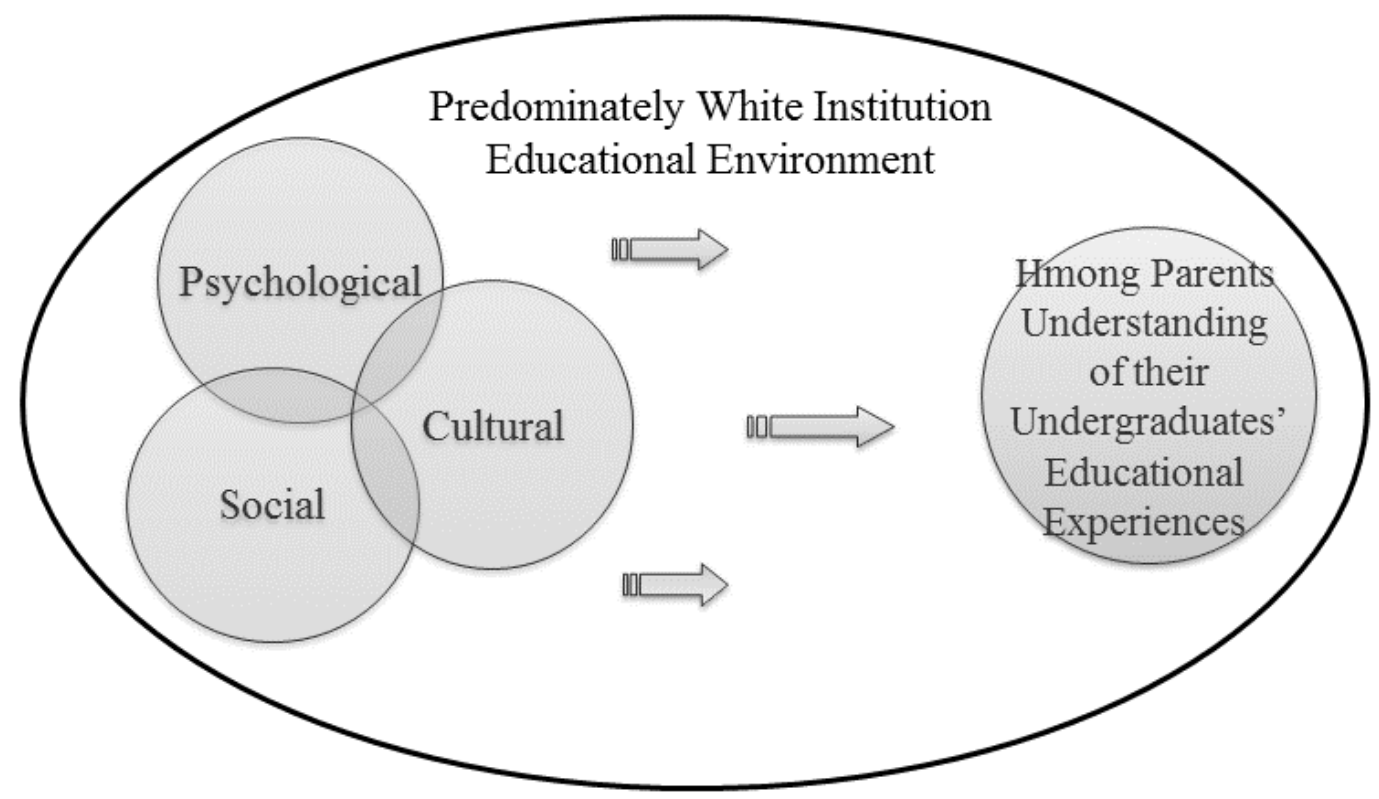

Figure 1. Psychosociocultural Model (Gloria \& Rodriguez, 2000)

More recently, the model has served as the theoretical basis to explore parents' understanding of their students' educational experiences. For example, Castellanos, Gloria Herrera, Kanagui-Muñoz, and Flores (2016) implemented the PSC approach with Latina/o parents, finding that the dimensions were collectively evident and had utility as to how they understood, supported, and held concerns about their high school-aged child. Most recently, Her and Gloria (2016) reported utility in the approach to understand Hmong parents' self-efficacy beliefs, expectations, and cultural values relative to their educational encouragement of their son/daughter. For the current study, the PSC approach serves as the study's theoretical basis to explore Hmong parents' perspectives and "college knowledge" of their Hmong American undergraduates' educational experiences and supportive role for their child.

\section{Study Purpose and Guiding Research Question}

The study's purpose is to assess Hmong parents' support of a son or daughter who was an undergraduate at a predominantly White four-year institution. The guiding research questions use a psychosociocultural approach (Gloria \& Rodriguez, 2000): 
1) to understand Hmong parents' perceptions, values, and attitudes of their undergraduates' university experience;

2) to examine how they provide support; and

3) to ask for recommendations for how educational institutions can support them and their children.

Despite the inconsistent findings regarding the role of parents for Hmong students, we anticipated that Hmong parents would provide culturally-grounded support specific to Hmong culture through direct behaviors and general values for higher education as a means for a better life (DePouw, 2003; Lamborn \& Moua, 2008; Ngo, 2013; Swartz et al. 2003). Similarly, it was anticipated that the notion of educational support would be constructed from a contextual and cultural Hmong-specific perspective.

\section{Method}

\section{Study Setting and Procedure}

After securing Institutional Review Board approval, Hmong parents residing in a Midwestern city were recruited using nonparametric sampling, through Hmong and Asian American student organizations, Southeast Asian American advising office, and other affiliated university campus offices that have connections to Hmong communities. Participants were interviewed in the dialect of White Hmong in a setting of their choosing (i.e., all chose their homes) by two members of the research team (Hmong female and male, as recommended by Her \& Gloria, 2016) for approximately 90 minutes. Parents were informed of their voluntary participation and right to withdraw at any time. As appreciation for study participation, parents were provided with a twenty-dollar gift certificate to a local Hmong grocery store. Interviews were audio-recorded, transcribed, translated, coded, and analyzed by the research team.

\section{Interview Protocol}

The research questions and follow-up questions were formulated within the psychosociocultural framework (Gloria \& Rodriguez, 2000) and addressed parents' education, understanding of college, support, values, and attitudes. Questions regarding parents' education addressed their experiences and messages they received from their parents about education. Parents' understanding of college addressed what they knew about their child's school, whether they had been to campus, and what they told their child about college or education. The support 
and values questions asked parents to provide examples of how they have provided support to their child(ren) while they were in college. Parents were asked to address their hopes and expectations for their child(ren) while in college and after they graduated. Last, parents provided advice for university personnel to support Hmong undergraduates and parents.

\section{Hmong Parents}

A total of eight sets of Hmong parents who were married and two single mothers (one widowed, one separated from her husband), for a total of 10 mothers and 8 fathers, participated. Parents ranged in age from 42 to $72(M=53.61$ years, $S D=7.76)$. One father $(5.6 \%)$ was born in Vietnam while all others (94.4\%) were born in Laos. Parents had resided in the US for an average of 21.22 years $(S D=5.02)$, ranging from 15 years to 30 years. Half of the Hmong parents (three fathers and six mothers) were employed at the time of interview. All parents indicated speaking White Hmong at home with their children, with four sets of parents also speaking English. The number of children per family ranged from 4 to $11(M=6.67, S D=2.54)$.

Parents were asked to focus on one child for the interview. Fourteen parents chose a daughter, one set of parents chose a son, and one set of parents chose a daughter-in-law. They reported the child's college student standing as four sophomores (22.2\%), three juniors (16.7\%), eight seniors (44.4\%), and three fifth-years (16.7\%).

Regarding the level of parental educational in their homeland of Thailand and Laos, seven mothers and one father declared having no formal education, three mothers and six fathers indicated having some grade school, and one father reported receiving a high school or GED education. In the US, most of the parents did not have any formal education (nine mothers, five fathers). For one set of parents, the mother had a two-year college degree and the father had a masters' degree. When asked if given the opportunity to attend school, 13 reported not wanting to because they were "too old to learn" and "there is no one to pay for the bills at home." Nine of the parents (four mothers and five fathers) wanted to return to school to learn basic English language and communication skills.

\section{Team Member Narratives and Data Trustworthiness}

The study team consisted of eight members, all of whom are Hmong, and included four undergraduate students, three masters' students, and one doctoral student representing multiple areas of study (e.g., Counseling Psychology, Educational Leadership and Policy Analysis, 
Human Development). The research team provided a unique and supportive academic context: social and cultural resources and support to conduct research under the mentorship of more advanced doctoral students and a faculty advisor. Given the nature of a qualitative study and the researchers' lived experiences as Hmong individuals attending a predominantly White institution, potential researcher biases (e.g., university does not involve Hmong parents or communities as part of the learning community), assumptions (e.g., Hmong parents would be hesitant to share their narratives), and experiences (e.g., microaggressions as Hmong students on campus) were considered.

Biases and assumptions related to the researchers' personal values were discussed and managed throughout the stages of analyses to ensure data trustworthiness (Lincoln \& Guba, 1985). To establish data credibility, the team members openly addressed and discussed biases to ensure that the analyses were credible, dependable, and as close to the parents' narrative as possible. The team members also gained concensus at each analysis stage before proceeding to the next step. For the transcription and translation, two team members worked to ensure dependability and accuracy of the data. Each analysis stage was also audited by the faculty lead to ensure confirmability of the data. Finally, to address transferability of the data, the researchers included parents with a range of educational experiences (Lincoln \& Guba, 1985). After the first two interviews with parents who did not have formal education, the researchers intentionally sought to recruit parents who had some exposure to educational systems.

\section{Process of Analysis Procedure}

The research team used LeCompte's (2000) multi-step content analysis to analyze the data. In the first step, the researchers transcribed, translated (Hmong to English), cleaned, and organized the transcripts in preparation for data analysis. The second step involved the researchers identifying items through a line-by-line coding for unit of analysis. Step three required the researchers to determine groups and categories based on the line-by-line coding to assemble taxonomies of item sets. The fourth step involved discussion and identification of emergent themes and patterns. Finally, the team's last step was to create meta-themes based on emergent themes and patterns that were specific to mothers, fathers, and both parents (See Table 1). Quotes were also identified during this step to help illustrate the meta-themes. 


\section{Emergent Themes and Discussion}

In analyzing the narratives to reveal overarching emergent themes, there were themes that were specific to both parents, mothers, and fathers regarding their educational experiences. The following describes each emergent meta-theme and illustrated with quotes.

\section{Niam Thiab Txiv Txoj Kev Txawj Ntse (Parents' Wisdom)}

Three emergent meta-themes resulted from the parents' narratives. The meta-themes drew from the parents' strengths and were clearly steeped in cultural understandings, cultural and familial capital of great importance within the educational setting (Castellanos et al., 2013; Yosso, 2005). These meta-themes countered the current literature depicting Hmong parents as being unaware and uninvolved in their children's education (Ngo, 2008).

My story, a different future for you. Similar to the Hmong cultural traditions that are oral-based, information is passed on from one generation to the next through stories, songs, conversations, gatherings and daily interactions with one another (Xiong, 2009). Hmong parents use their own experiences and life narratives to inform the way they support their child in higher education. Parents described their hardship of growing up in a poor farming community, not having the opportunity to go to school, and escaping the Vietnam War with the intent of motivating and teaching their children to study harder in school. One parent expressed:

I would share my life story with all of my children and they realized that I have a very poor life and therefore they [need to] study hard. They would realize that since their mother is so poor, they would need to work hard from now on.... I would use my personal life story to teach my children.... Some of my children are unable to understand my story but others are able to and use it as a motivation to improve their life. It is a life lesson for them to learn that my mother passed away when I was very young, and I was very young and I was very poor. I would share with them that when I was a little girl about 8 or 9 years old, I really want to go to school. Because I have no parents to support me and therefore I have no education.

Describing their previous hardships growing up, one parent stated, "I ask them to look at me and see what my life is like. I want them to look at my life before making the decision to not go to school." The parents expressed wanting their children to be educationally successful, get a 
stable job, and not live such a hard life like theirs. The parents felt that not having an education, they were not able to sufficiently provide for their family in the US. They expressed a desire for their children to have a different experience than their own, as one parent aptly stated, "I work very hard; and I am tired, and I want her to go to school, do well in school, and able to find a good job. So that she is not like me. So that she doesn't have a hard life."

Different from their parents, the Hmong parents in this study encouraged their children to pursue higher education, as they believed the key to being successful in the US is education. Parents used their non-academic knowledge to academically support their children. They equated their experiences of hard work on the farm resulting in a good harvest to hard work in school resulting in a good educational outcome. For example, one parent indicated,

I have never gone to school so I don't know [what to tell my child about school]. But my parents would teach me how to farm and do daily chores around the house. They would teach me to work hard in whatever I do.

The parents taught their children to be patient with education and recognize that success is not easy to achieve, yet with rau siab they believed firmly their children will be successful.

I'm doing all I can yet I wish I could do more. Woven throughout the parents' narratives was the belief that they were doing all that they could to support their child yet they desired to do more. The parents wanted to assist with finances, homework, or understanding their child's educational experience; however, they were unable due to limited resources or lack of college knowledge. Nonetheless, parents had the strong desire to do all that was in their means, as one parent stated, "We want to do everything." Parents described providing multiple levels of support for their child, from praying for them to cooking and cleaning. By not asking for household assistance, parents sought to provide their child time to study. Another parent stated,

I would only be able to help them by staying home and cooking for them. I would provide them with enough food. I would clean their clothes for them. So when they come home, they would have food to eat. I would not allow them to do chores at home because I am still able to do it and they have a lot of work to do. I want to give them time, have food ready for them to eat and have some time to rest and study. And when they are tired, let them rest too. So that when they are studying, they are not tired. 
This type of support from Hmong parents is consistent with other studies that found that Hmong parents engage in concrete and subtle ways such that students have time to do homework as means to support education (Juang \& Meschke, 2017). This support included dropping off and picking up their children at school at all hours of the day, even at times that meant being late or missing work. For example, one parent indicated,

"[I] buy a car for my children to drive to school and also for me to drop them off at school. Even if the child goes in the morning I take them and even the child goes in the evening I will take them. So, even if they go for 30 minutes I will go pick them up; even if they go for 10 minutes I will go pick them up."

After recounting multiple ways in which they had supported their children in order to go to school, one parent nonetheless expressed, "We would want to help them as much as possible but we can only think about it and can't do it." Similarly, a parent indicated,

I don't know how to help. It is really up to her, if she wants to learn. The only thing I could do is, I tell her, "You are going to have a test tomorrow, I will pray for you about ten o'clock so, you'll do good." I don't know how more to support her.

Despite describing a litany of ways that they supported their children, the parents minimized all that they were doing. One parent said, "[o]ur only hope to support her is through words. Only good words. There's nothing else [we can do]. The parents engaged in peb qhuas or daily words of encouragement and praise to assist their children through difficult times; words that were steeped in cultural notions of working hard for the greater good. One parent said, "When she gets home from school, we (parents) praise her and support [her] for her efforts. This helps her to be motivated to continue with school, this is how you support children."

An important distinction for the parents, however, is that the fathers' encouragement focused on their child's effort and work ethic and the mothers' showed their encouragement through expression and actions towards their child's school work to manifest success in school. Holding consistent the notion of rau siab, or to work hard and aspire to advancement through one's focused efforts, perseverance, and sacrifice. For example, one parent indicated, 
"I can only support her through words by telling her rau rau siab kawm ntawv (to study hard). I do not [know] what else to say and only tell her to continue studying hard so that is worth my effort of raising her here in the United States.

The finding that Hmong parents worked to instill important life cultural values as part of peb qhuas to encourage a good life is consistent with the literature (e.g., Juang \& Meschke, 2017).

Qhib siab lug paub peb (Know us with an open heart). The parents clearly described a lack of communication between them and the university yet knew that such communication is a best practice to support Hmong students. Aptly stated, one parent indicated, "If the university can support our children then they are able to support us too." Knowing and understanding the parents required knowing values, beliefs, and practices and the importance of education as a means of familial and community advancement (Her \& Gloria, 2016). The Hmong parents wanted the university to know that they have values that need to be understood and respected. One parent indicated,

I am very happy that they [the faculty] really teach my children, and the teachers know that at school they have their own rules yet at home they [my children] have their own rules. For me, when my children go to school [they follow the rules]; when they [children] come home they would need to follow my rule at home too.

The parents wanted the university to acknowledge that their histories, narratives, and cultural orientations of family and clan were different from the university system and that because of this they believed that the university needed to take responsibility for knowing them more fully to ensure their students' success. Within this conversation of being known, it was the mothers who identified that the communication between the university and Hmong parents that they could engage their role of monitoring the well-being and academic success of their child. Although both parents asked for more communication, it was the mothers who expressed having the responsibility to provide emotional and wellbeing support to their children within the Hmong family, a process consistent with other research (Lamborn \& Moua, 2008).

In the process of being known, the Hmong parents believed that with siab ntev (patience) and qhib lub siab (open heart) university personnel could best know them and subsequently 
genuinely care for their undergraduate children. They expressed wanting the university to know them in order to support their children and importantly to do so "with an open heart." Consistently, the parents asked for patience, as one parent indicated, "I want to ask the teachers to please teach our children and even with those that are not as good [those who are not performing well in school] to be patient and teach them." The parents asked that their children were cared for and valued equally. One parent asked,

I would want them [professors] to respect our black hair children equally like the White students. I would want them to give them the idea [that] English is the second language so it is difficult. They should not think that our children are stupid because they are very smart too, but because English is their second language so it is very hard. If our students ask for clarification, I would want them to be patient and explain to our children so they can [understand] like other students too. I want them [faculty] to value our students and teach them the same way as others.

Likewise, the parents knew that to "know them" would require hiring Hmong faculty and staff as conduits by which to know them. Indeed, being known meant being represented on campus. The parents also wanted to be invited to come on campus. When asked if they had been on campus, one parent said,

To walk around the campus and classroom, no, we have not. But, in terms of that hill, I have sent my children to every single street that they have on that campus. But I have never been to the classroom at all. I have been dropping them [their children] off for nine years now and I know every street and every location on campus, but I have not been to the classroom at all. I have not been to the library either.

Another parent asked to visit the campus stating,

We would like to go visit and see [the campus] because our children have been there for awhile and we have never seen their classes. We would want to know how their school is set up and what they [the buildings] look like inside. How many professors are there and how long has the university been open. I would want to see it. 
At the same time, it was the mothers who recognized the support their child did receive from university staff and expressed happiness, thanks, and appreciation for those who had helped and supported their children in their educational endeavors. By assisting Hmong students from a similar stance of an open heart, the parents believed it would decrease stress levels, increase selfconfidence, and bolster the students' own hearts in continuing to learn what they desire.

\section{Niam Txoj Kev Txawj Ntse (Mothers' Wisdom)}

Two emergent meta-themes resulted for mothers. Similar to the Hmong literature indicating specific gender roles for fathers and mothers (Trimm, 1994), the themes reflected the cultural gender-specific roles that Hmong mothers engage in their children's educational pursuit.

I didn't so you will: Regaining opportunities unrealized. Connecting to their identity as women growing up in Laos and Thailand, mothers were not allowed to attend school and received messages that the responsibility of a Hmong woman involved fulfilling the roles and responsibilities of a housewife, daughter, daughter-in-law, and mother (Donnelly, 1994; Trimm, 1994). They received messages that Hmong females were considered "bad" daughters if they went to school because they would be unable to fulfill these important roles for the family and farm. By adhering to strict gender roles of their family and engaging in cultural roles to maintain family livelihood, mothers felt they were unable to fulfill their full potentials. In describing their experience as a daughter, one mother stated,

I have three daughters and four sons. I would tell my daughters that even though I did not have an education all of them should go to school. It doesn't matter whether they are a son or a daughter; I want all of them to go to school. I don't want them [children] to be like me where all of my brothers have an education except for me. As for me, I am sad that my parents did not give me the same opportunity I am giving to my children because I would be educated and able to see further [into the future] than now.

As such, as mothers, they were adamant to do whatever it takes to help their children realize their full potentials and not undergo opportunities unrealized as they did. This involved allowing their child to study any subject, as one mother stated, "They study anything as long as they liked it [because] it has to be something they like in order for them to learn," so they could graduate with a good-paying job. Further, it was the mothers who indicated that they would go 
along with their child's choices of major even if they disagreed as long as it ultimately yielded family advancement. These mothers also believed that despite their lack of college knowledge and limited educational attainment, as long as their children "mloog mloog lus" and "rau siab" (are well behaved and work hard by staying focused on school), this would help them be successful in school in a way that they were not. Mothers believed that "those mloog mloog lus [are] able to learn in school and finish, they are the ones that work hard."

I support you, you will support me. Mothers linked how they support their child back to their role as Hmong women. Specifically, mothers identified their support of "ua zaub mov" (providing a home-cooked meal) as an essential contribution to their children's education and as a way to lessen the stress and daily burden on their child. Hmong women have a strong cultural and identity connection to providing home-cooked meals, as they perceive Hmong food to be representative of them and a reminder of who they are (Vue, Wolff, \& Goto, 2011). Providing food for one's child represents the wealth of support and love that mothers have for their child, and the food serves as a reminder of their Hmong identity. In return for their support, the mothers held a cultural expectation that when their children graduate and are self-sustaining, their children will provide and care for them in their old age. One mother recounted this wisdom,

My hope is that they will be able to provide for themselves. When we are old and poor, they will help us out and provide food for us to eat, that is our biggest hope. The elders always said, "You farm for when you are hungry, you have children to prepare for when you are old, can't help yourself anymore."

Although speaking about basic needs (i.e., having food and shelter), the mothers addressed the cultural premise of feeding and sheltering family as an expansive value of familycenteredness and the importance of having harmonious family relationships in old age (Nguyen \& Seal, 2014), as expressed by a mother, "When she graduates, our hope is that when we don't have anything to eat, she will give us something to eat. And when she is educated enough, we hope that we won't die of starvation."

This narrative aligns with research and the traditional Hmong belief that through farming one will be taken care of (Lee, 2004; Nguyen \& Seal, 2014); mothers expressed a similar notion that through education they would have "food to eat." The mothers expressed the cultural belief 
that their efforts would be reciprocated through their children's "kev rau siab" (hard work) in education and thus they would do all they could.

\section{Txiv Txoj Kev Txawj Ntse (Fathers' Wisdom)}

Consistent with literature regarding Hmong males serving as the protector, provider (Moua, 2003; Yang, 1997), and "ultimate authority as head of the household of one's family" (Trimm, 1994, p. 39), two complementary and closely-related meta-themes emerged specifically for the Hmong fathers. These meta-themes included fathers acknowledging the needs and challenges of negotiating the duality of traditional Hmong and US cultures as well as the needed process to take care of oneself as a means to take care of others.

Negotiation of contrasting systems. The values orientation of the Hmong focus on family (clan) and community is at the core of the ideological and conceptual contrast for Hmong in the US (Trimm, 1994). Although Hmong gender roles have shifted (Lee, 2004), the study's findings align with the notion that Hmong males have the responsibility to negotiate "the outside world" for themselves and their family (Trimm, 1994, p. 38). The fathers knew that they had to figure out and merge contrasting cultural systems and practices as a means of familial survival. As head or familial point person, the fathers sought to understand and negotiate the dual systems of their traditional Hmong beliefs and practices and those in the US. As a way to express this process, the researchers carefully engaged in cultural process with the fathers (maintaining the cultural role of male elder symbolizing strength and their place with younger members of the Hmong community). The fathers discussed the different educational systems by comparing their own grade school experiences to those of their children's higher education institutions as a way to apply what they know about school to the way they best support their children in higher education. The fathers consistently indicated that "The way we study in Laos is different than here." One father recounted,

When we were back in Thailand, it doesn't matter whether you are big or small [height/ages], as long as you did well in classes and that's where you are place. Is not like here (in the US) where they count your ages. Even if you are tall [old], if you have never learn it before, you will have to start in the lower grade. If you are small [young], you can't be in the higher grade even if you are doing well in school, this is not the case in Thailand. 
Further, fathers believed that their roles included determining how to merge the needs of the individual and the collective (family) in a way that appeared as being strong regardless of the difficulty to do so. For example, one father subtly expressed concern in needing to manage contrasting processes for his children as he stated,

Education in Laos is different from the United States. In Laos, the teachers discipline the students very well.... In this country, it seems like at school there is a lot of freedom. It is different from when we were in school in Laos.

Self care $=$ Care for others. As head of the household and financial provider for the family, the Hmong fathers expressed their heart's desire to fulfill this role. One father stated,

I don't have many concerns, and the only concern is that when my children are in college, it will require a lot of money and how can I support them financially as my heart desires. What I am concerned about is how I am going to support them financially when they need money. If they need money and I cannot support them, they will have to take loans.

Yet, in caring for their children they knew that they needed to put their own needs first as a route to take care of others. In this way, the fathers indicated the complex, nuanced process and strength-based sacrifice of distancing themselves from their families in order to take care of their family. In describing this process, one father stated

I don't really want to know [how daughter is doing in school] because I want everything to be good. And when I find out that there is something bad, I would get sick. I would only ask, how she is doing. And she [wife] tells me that she [daughter] is doing fine like always. I don't want to know anything else.

Indeed, Hmong fathers have been perceived as "hardworking but absent" (p. 411) by their pre-teens and adolescents (ages 11 to 18) (Lamborn \& Moua, 2008), yet by stepping away they know that they were providing for their families to the best of their abilities.

Knowing how challenging it is to negotiate systems as a Hmong male, the fathers were aware that they needed to work hard, which might lead to being overwhelmed or sick; otherwise, they could not engage in the critical role of providing for others. Framed and understood as a 
process of strength to do everything that one could to support one's family financially, one father explained the importance of caring for others is through caring for themselves first.

We think too much and become crazy and get sick. We won't be able to do anything and we won't' be able to help. We won't' be able to say anything... we can have a stroke and that would be the end of it [being able to take care of one's family].

By distancing themselves and not knowing or engaging in their children's daily educational details, a process whereby fathers may by default not be aware of their child's activities (Lamborn \& Moua, 2008), the fathers noted they could maintain their intentional focus to work hard (sometimes two and three jobs) in order to take care of family. Overall, the process of self-care in order to care for others aligns with Hmong gender roles for fathers who are expected by families and communities to serve as provider and protector (Moua, 2003).

Table 1: Emergent Themes by Parents, Mothers and Fathers

\begin{tabular}{lll}
\hline Emergent Themes & Illustrative Statement & Parents \\
\hline $\begin{array}{l}\text { My story, a different } \\
\text { future for you. }\end{array}$ & $\begin{array}{l}\text { "I ask them to look at me and see what my life is like. I } \\
\text { want them to look at my life before making the } \\
\text { decision to not go to school." }\end{array}$ & Parents \\
\hline $\begin{array}{l}\text { I'm doing all I can yet I } \\
\text { wish I could do more }\end{array}$ & $\begin{array}{l}\text { "We would want to help them as much as possible but } \\
\text { we can only think about it and can't do it." }\end{array}$ & Parents \\
\hline $\begin{array}{l}\text { Qhib siab lug paub peb } \\
\text { (Know us with an open } \\
\text { heart) }\end{array}$ & $\begin{array}{l}\text { "If the university can support our children then they are } \\
\text { able to support us too." }\end{array}$ & Parents \\
\hline $\begin{array}{l}\text { I didn't so you will: } \\
\text { Regaining opportunities } \\
\text { unrealized }\end{array}$ & $\begin{array}{l}\text { "I would tell my daughters that even though I did not } \\
\text { go to school. It doesn't matter whether they are a son } \\
\text { or a daughter; I want all of them to go to school." }\end{array}$ & Mothers \\
\hline $\begin{array}{l}\text { I support you, you will } \\
\text { support me }\end{array}$ & $\begin{array}{l}\text { "My hope is that they will be able to provide for } \\
\text { themselves. When we are old and poor, they will help } \\
\text { us out and provide food for us to eat that is our biggest } \\
\text { hope." }\end{array}$ & \\
\hline $\begin{array}{l}\text { Self care = Care for } \\
\text { others }\end{array}$ & $\begin{array}{l}\text { "I don't have many concerns and the only concern is } \\
\text { that when my children are in college, it will require a }\end{array}$ & Fathers \\
\hline
\end{tabular}


lot of money and how can I support them financially as

my heart desire."

\section{Discussion and Implications}

The study's findings clearly bring to light that Hmong parents' "pedagogies of the home" (Delgado Bernal, 2002, p. 109) are the core value to support their children in higher education. It is through the familial capital (Yosso, 2010) that parents clearly support their undergraduate son or daughter in college (Lor, 2008), and that universities must acknowledge and bolster to find culturally relevant and meaningful ways to support Hmong American students' success and persistence to graduation. Much like students of color who "often feel that their histories, experiences, cultures, and languages are devalued, misinterpreted, or omitted within formal educational settings" (p. 106), similarly the Hmong parents' perspectives about what culturally and historically-based support that they could provide their children for the higher education context. Simply stated by Her and Gloria (2016), "First and foremost, it is clear that the role Hmong parents play in their children's educational advancement is salient and cannot be overlooked (p. 27)."

First, Hmong parents are clearly involved with their daughter/sons who are attending higher education in psychological, social, and cultural ways and thus it is incumbent that the university get to know and engage Hmong parents and communities in ways that reflect respect for their wisdom and ways in which they provide support for their Hmong children. Importantly, faculty, staff, and student programs (e.g., first-year student program, residential units) must be willing to affirm Hmong parents' cultural practices and messages (e.g., ua siab ntev, rau siab) as a means to create community partnerships to engage student learning. For example, creating an advisory panel of Hmong parents who can identify needs and provide feedback as well as seek information about the educational process (e.g., gain college knowledge) is suggested as a way to involve and gain Hmong parents' wisdoms in best supporting their Hmong children in higher education.

Second, as Hmong parents asked to know more about the campus (e.g., being invited to know the campus and information about what college entails), there was an unstated need and expectation for this information to be delivered in a culturally honoring and congruent way that represents the university effort to know the parents with "an open-heart." That is, campuses must consider how their parent programs are implemented to specifically meet the cultural needs of 
their Hmong communities; for example, providing campus visits that are hosted entirely in Hmong by Hmong faculty, staff, and students, along with translated materials and information about resources offered. The campus visit should integrate Hmong practices (e.g., traditional songs to honor events, gifts to acknowledge reverence and importance of parental roles) throughout the day to validate the importance of the Hmong culture (Her et al., 2012). Likewise, having university administrators (e.g., deans or provosts) as well as faculty present, who would be recognized as university "elders," would help parents feel that they are being appropriately welcomed. University actions that clearly convey cultural acknowledgment and honor of Hmong parent experiences, practices, and pedagogies are needed.

Finally, the actions and efforts of the parents were clear and meaningful despite the parents indicating that even though they did not know the detail of the school process, they knew how their children were doing in school. Although the parents held the perspective that they did not have much to offer, they engaged in numerous ways to support their children and indeed had emotional, cultural, and practical supports to provide their children to persistence on a daily basis in higher education. In this way the parents engaged in micro-success educational processes (Castellanos \& Gloria, 2007) as they shared their narratives as a way to inform how they supported their children. Indeed, it is through these cumulative and meaningful processes that the Hmong parents serve as the foundational support for their children, upon which the university would do well to acknowledge, access, and partner. By doing so, the university can create a learning setting in which different ways of knowing are valued and brought into the learning setting (Castellanos et al., 2016; Delgado Bernal, 2002; Her \& Gloria, 2016; Yosso, 2010).

\section{Limitations of the Study}

Complementary to the study's findings, there are several methodological and contextually based limitations. First, as this is one of the first theoretically-driven qualitative studies addressing Hmong parents about their support of Hmong child who is an undergraduate, additional studies which gain continued narrative is needed. As the Hmong communities from which the parents were recruited were relatively small and have strong collective and community connections by clan and relationships, the parents may have been constrained in their responses. As there may be hesitancy by Hmong parents or families to share information that may reflect poorly on their clan, the narratives gained may have been overly positive in describing parents' encouragement and support. For example, the interviewers were known by their parents or clans 
of whom many were community elders and/or clan leaders. At the same time, it was because the interviewers were known via their clans that the parents shared their narratives. The Hmong parents may have underreported their actions as a way to be modest or humble (i.e., parents will praise children at home but not outside of the home). Also, despite working in teams to crosscheck the translation and transcription of the parent interviews, specific attention was paid to the translation of the Hmong word "yus" as "you" rather than "I" or "me" as parents and interviewers used English and Hmong words interchangeably in some of the transcripts.

Next, the Hmong parents were asked to answer the questions about a son or daughter (who were primarily daughters), they consistently as well as culturally addressed all of their children along with nej cov hluas (the young people) of their Hmong community; individuals who are expected to advance Hmong families and communities (Lee, 2007; Lor, 2008). This process was most directly revealed when the Hmong parents spoke directly to the interviewers as a community "daughter/son" telling us to rau siab (work hard to succeed educationally) and to use our education and knowledge to help Hmong communities. It was also from this space that the Hmong parents most fully engaged and shared their experiences and perspectives.

Finally, throughout the interview, there were multiple instances in which only the fathers answered questions. As the parents were interviewed as couples, there were many times where the father took the lead in response of questions and the mothers deferred to the fathers. For example, the mothers would reference or repeat what the father said or would respond as "we" versus "I" to questions that were directed to them as mothers. As such, the interviewers asked several of the mothers for their response given their cultural deferment to their husband in that they had already responded yet were respectful in doing so.

\section{Future Methodological Considerations and Research}

For future research with the Hmong parents, there are several methodological and inquiry considerations. First, if the interviewers are students themselves, they need to consider that the Hmong parents may likely engage them as "their children" in providing advice and direction about education. This process is culturally consistent within Hmong communities and can be integrated such that the interactions are respectful and congruent to elder and young person interactions. Another methodological consideration is to set the foundation of cultural and familial capital (Yosso, 2010) for the Hmong parents as part of the parent recruitment. Letting Hmong parents know that they have wisdom that the educational system needs to know is a 
critical part of the recruitment and interview process. As some parents were not formally educated or had limited education, reorienting their contributions as important may be necessary to build initial community rapport and openness to share their processes. Finally, interviewing mothers and fathers separately, either individually or in focus groups, with the gender of the interviewers considered (Her \& Gloria, 2016), may also yield additional narrative and perspective.

Parents discussed the importance of having an educated child who can advance their family and community (Lee, 2007), yet maintain the cultural belief that when their daughters marry into a different family, she takes the education with her (Lee, 2004). Therefore, it is important to explore how parents take ownership of raising an "educated son" versus an "educated daughter." As previous research revealed differences in support by parent-child pairing (Her \& Gloria, 2016), specific questions by parent relative to a daughter or son may yield fuller and more specific cultural responses. Similarly, it may inform the cultural relationships of fathers in support of their nyab (daughter-in-law), with whom they have no personal connection, a culturally-appropriate relationship with Hmong cultural context (Donnelly, 1994), yet familial obligation as provider and protector of one's family. The complexity of this culturally-nuanced relationship warrants continued exploration for married Hmong females in higher education.

Additionally, as parents stated that they would support their child's major or career choice, it is traditionally a son's responsibility to provide for the parents during old age (Lee, 2004). Thus, exploring how this value may influence the type of career path parents encouraged their sons to pursue, knowing that their future livelihood may rely on whether their sons can provide for them or not. Moreover, it is questioned as to whether this expectation extends to daughter-in-laws who become part of the family and are expected to contribute and assist in the caring of parents during old age (Donnelly, 1994). One father also suggested that the research team explore the reasons that Hmong children who were born and educated in Laos have more degrees (e.g., lawyers, doctors) than the Hmong children who were US-born and educated.

\section{Conclusion}

Indeed, the Hmong parents' serve a pivotal role in the psychosciocultural persistence processes and success of Hmong undergraduates. As the Hmong parents spoke directly to the researchers, one mother provided sage advice to the young people. She acknowledged that although it is us, the students and researchers, who were succeeding educationally, we should 


\section{A Psychosociocultural Understanding}

remember that we got to this point because of our parents; we needed to remember it was from the power of our niam txiv txoj kev txawj ntse (parents' knowledge) that we were succeeding. Indeed, universities would do well to access the wisdom and powerful resource of Hmong parents as they support Hmong students' persistence to graduation.

Author Note: "Niam Txiv Txoj Kev Txawj Ntse” translated to parents' path of knowledge; what we know which refers to the knowledge parents have provided for their undergraduate child. Shared *third and ${ }^{\wedge}$ fourth authorship. The authors thank Saengthong Douangdara, Michelle Xiong, and Hnub Vang for their consultation and support of this study. 


\section{References}

Castellanos, J., \& Gloria, A. M. (2007). Research considerations and theoretical application for best practices in higher education: Latina/os achieving success. Journal of Hispanic Higher Education, 6, 378-396. doi: 10.1177/1538192707305347

Castellanos, J., Gloria, A. M., Herrera, N., Kanagui-Muñoz, M., \& Flores, C. (2013). ;Apoyamos la educación de nuestros hija/os!: How Mexican parents' college knowledge, perceptions, and concerns effect their parental support of their child. The Journal of Latino-Latin American Studies, 5(2), 85-98. doi:10.18085/1las.5.2.8xn051203217v35g

Chung, R. C.-Y., \& Bemak, F. (2006). Counseling Americans of southeast Asian descent: The impact of the refugee experience. In C. C. Lee (Ed.), Multicultural issues in counseling: New approaches to diversity (pp. 151-170). Alexandria, VA: American Counseling Association.

Delgado Bernal, D. (2002) Critical race theory, LatCrit theory and critical raced-gendered epistemologies: Recognizing students of color as holders and creators of knowledge. Qualitative Inquiry, 8(1), 105-126. doi: 10.1177/107780040200800107

DePouw, C. (2003). Familiar foreign: Hmong American students engaging and resisting in America. Paper presented at the Annual Meeting of the American Educational Research Association, Chicago. IL.

Donnelly, N. D. (1994). Changing lives of refugee Hmong women. Seattle, WA: University of Washington Press.

Faderman, L., \& Xiong, G. (1998). The Hmong and the American immigrant experience: I begin my life all over. Boston, MA: Beacon Press.

Fuertes, J. N., Sedlacek, W. E., \& Liu, W. M. (1994). Using the SAT and noncognitive variables to predict the grades and retention of Asian American university students. Measurement and Evaluation in Counseling and Development, 27, 74-84.

Gloria, A. M., Castellanos, J., Lopez, A. G., \& Rosales, R. (2005). An examination of academic nonpersistence decisions of Latino undergraduates. Hispanic Journal of Behavioral Sciences, 27(2), 202-223. doi: 10.1177/0739986305275098

Gloria, A. M., Her, P., Thao, B. J., Lee, D., Chang, S. Y., Thao, A., \& Aroonsavath, L. (2017). Tub txawj, ntxhais ntse: Experiences of Hmong American undergraduates. Journal of Family Diversity in Education, 2(4), 63-83.Retreived from http://familydiversityeducation.org/index.php/fdec 
Gloria, A. M., \& Ho, T. A. (2003). Environmental, social, and psychological experiences of Asian American undergraduates: Examining issues of academic persistence. Journal of Counseling \& Development, 81(1), 93-105. doi: 10.1002/j.1556-6678.2003.tb00230.x

Gloria, A. M. \& Rodriguez, E. R. (2000). Counseling Latino university students: Psychosociocultural issues for consideration. Journal of Counseling and Development, 78, 145-154. doi: 10.1002/j.1556-6676.2000.tb02572.x

Hamilton-Merritt, J. (1999). Tragic mountains: The Hmong, the Americans, and the secret wars for Laos, 1942-1992. Bloomington, Indiana: Indiana University Press.

Her, P., Chang, S., Thao, P., Thao, K., Gloria, A. M., Xiong, M., \& Douangdara, S. (2012). Hmong Parents' Day: Hosting a campus event for community advancement. Poster presentation at the Annual Conference of the Asian American Psychological Association, Orlando, FL, August 1, 2012.

Her, P., \& Gloria, A. M. (2016). Kev txhawb siab: Hmong parents' educational encouragement of their undergraduate daughter/son. Journal of Family Diversity in Education, 2(2), 19-34. Retrieved from http://familydiversityeducation.org/index.php/fdec

Inui, M. (2015). Hmong women and education: Challenges for empowerment in the Lao PDR. Hmong Studies Journal, 16, 1-24. http://hmongstudies.org/InuiHSJ16.pdf

Juang, L. P., \& Meschke, L. L. (2017). Hmong American young adults' reflections on their immigrant parents. Journal of Family Issues, 38(9) 1313 -1335. doi: $10.1177 / 0192513 X 15581658$

Karon, J., Long, D., \& Veroff, D. (2003). Wisconsin's Hmong population: Census 2000 and other demographic trends. University of Wisconsin Extension \& Applied Population Laboratory. University of Wisconsin-Madison.

Lamborn, S.D., \& Moua, M. (2008) Normative family interactions: Hmong American adolescents' perception of their parents. Journal of Adolescent Research, 23(4), 411-437. Doi: $10.1177 / 0743558407310772$

Lee, G. Y. (2005). The shaping of traditions: agriculture and Hmong society. Hmong Studies Journal, 6(1), 1-33. Retrieved from http://members.ozemail.com.au/ yeulee/Culture/The\%20Shaping\%20of\%20Traditions.html

Lee, S. C. (2007). The self-rated social well-being of Hmong college students in Northern California, Hmong Studies Journal, 8, 1-19. http://hmongstudies.org/SLeeHSJ8.pdf 
Lee, S. J. (2004). Hmong American masculinities: Creating new identities in the United States. In N. Way \& J. Y. Chu (Eds.), Adolescent boys: Exploring diverse cultures of boyhood (pp. 13-30). New york, NY: New York University Press.

Lee, S., Xiong, C., Pheng, L. M., \& Vang, M. N. (2017). The model minority maze: Hmong Americans working within and around racial discourses. Journal of Southeast Asian American Education and Advancement, 12(2), 1. doi: 10.7771/2153-8999.1153

LeCompte, M. D. (2000). Analyzing qualitative data. Theory into Practice, 39, 146-154. doi:10.1207/s15430421tip3903_5

Lin, M. M., Her, P., \& Gloria, A. M. (2015). Kawm ntawv qib siab: Understanding the psychosociocultural educational experiences of Hmong American undergraduates. Journal of Southeast Asian American Educational Advancement, 10(1), Article 7. doi: 10.7771/21538999.1123

Lincoln, Y. S., \& Guba, E. G. (1985). Naturalistic inquiry. Newbury Park, CA: Sage.

Lor, P. (2008). Key life experiences contributing to Hmong Students' matriculation. Multicultural Education, 16(1), 39-47. Retrieved from https://files.eric.ed.gov/fulltext/EJ822397.pdf

Moua, T. (2003). The Hmong culture: Kinship, marriage, \& family systems. Unpublished Master's thesis, University of Wisconsin-Stout, Menomonie, WI.

Ngo, B. (2008). The affective consequences of cultural capital: Feelings of powerlessness, gratitude and faith among Hmong refugee parents. Journal of Southeast Asian American Education \& Advancement, 3, 1-14. doi: 10.7771/2153-8999.1100

Ngo, B. (2013). Cultural consciousness among Hmong immigrant leaders: Beyond the dichotomy of cultural essentialism and cultural hybridity. American Educational Research Journal, 50(5), 958-990. doi: 10.3102/0002831213494262

Nguyen, A. L., \& Seal, D. W. (2014). Cross-cultural comparison of successful aging definitions between Chinese and Hmong elders in the United States. Journal of Cross-Cultural Gerontology, 29(2), 153-171. Doi: 10.1007/s10823-014-9231-z

Paik, S. J., Rahman, Z., Kula, S. M., Saito, L. E., \& Witenstein, M. A. (2016). Diverse Asian American families and communities: Culture, structure, and education (Part 1: Why they differ). School Community Journal, 27(2), 35-66. Retrieved from https:/files.eric.ed.gov/fulltext/EJ1165621.pdf 
Sengkhammee, J. T., Her, P., Gloria, A. M., Lin, M. M., Thao, B. J., Cabinte, D. C., \& Aroonsavath, L. B., (2017). Txo kev nsthiab: Hmong American undergraduates' perceptions of intellectual phoniness and psychosociocultural persistence decisions. Journal of Southeast Asian American Educational Advancement, 12(1), Article 1, 1-19. doi: 10.7771/21538999.1139

Swartz, T., Lee, J. C., \& Mortimer, J. T. (2003). Achievements of first-generation Hmong youth: Finding from the Youth Development Survey. CURA Reporter, 33, 15-21. Retrieved from http://www.cura.umn.edu/sites/cura.advantagelabs.com/files/publications/33-1-Swartz-LeeMortimer.pdf

Tatman, A. W. (2004). Hmong history, culture, and acculturation: Implications for counseling the Hmong. Journal of Multicultural Counseling and Development, 32(4), 222-233. doi: 10.1002/j.2161-1912.2004.tb00629.x

Thompson, M. N., Johnson-Jennings, M., \& Nitzarim, R. S. (2013). Native American undergraduate students' persistence intentions: A psychosociocultural perspective. Cultural Diversity and Ethnic Minority Psychology, 19(2), 218. doi: 10.1037/a0031546

Trimm, J. T. (1994). Hmong values and American education. Equity \& Excellence in Education, 27(2), 36-44. doi: 10.1080/1066568940270208

Vang, T., \& Flores, J. (1999). The Hmong Americans: identity, conflict, and opportunity. Multicultural Perspectives, 1(4), 9-14. doi: 10.1080/15210969909539923

Vue, W., Wolff, C., \& Goto, K. (2011). Hmong food helps us remember who we are: perspectives of food culture and health among Hmong women with young children. Journal of nutrition education and behavior, 43(3), 199-204. doi: 10.1016/j.jneb.2009.10.011

Xiong, X. (2009). What does it mean to be "educated" from an oral culture: A study of traditional Hmong knowledge. Doctoral dissertation, University of Wisconsin-La Crosse.

US Census Bureau. (2016). American Community Survey 1-Year Estimates: Hmong alone. https://factfinder.census.gov/faces/tableservices/jsf/pages/productview.xhtml?pid=ACS_16_ 1YR_S0201\&prodType=table

Yang, K. (2003). Hmong diaspora of the post-war period. Asian and Pacific Migration Journal, 12(3), 271-300. doi: 10.1177/011719680301200302

Yang, X. (1997). Hmong men's adaption to life in the United States. Hmong Studies Journal, 1(2), 1-22. Retrieved from http://hmongstudies.com/HSJ-v1n2_Yang.pdf 
Yosso, T. J. (2005) Whose culture has capital? A critical race theory discussion of community cultural wealth. Race Ethnicity and Education, 8(1), 69-91. doi:10.1080/1361332052000341006 